\title{
EFFECTS OF LUCC RESULTING FROM TFFP LAND USE PATTERN IN THE YELLOW RIVER DELTA, CHINA
}

\author{
Xuegong $\mathrm{Xu}^{1, *}$, Xiaofeng Duan ${ }^{1}$, Richard Dawson ${ }^{2}$, Yanhua Liu ${ }^{1}, \mathrm{Yu}$ \\ $\mathrm{He}^{1}{ }^{1}$, Huifang Peng ${ }^{1}$, Chaowei Cui ${ }^{1}$ \\ ${ }^{1}$ College of Urban and Environmental Sciences, and Laboratory for Earth Surface Process of \\ Ministry of Education, Peking University, Beijing, P. R. China 100871 \\ ${ }^{2}$ China Agricultural University, Beijing, P. R. China 100083 \\ * Corresponding author, Address: College of Urban and Environmental Sciences, and \\ Laboratory for Earth Surface Process of Ministry of Education, Peking University, Beijing, \\ P. R. China 100871, Tel: +86-10-62767240, Fax: +86-10-62751187, Email: \\ xxg@urban.pku.edu.cn
}

\begin{abstract}
This paper traces the environmental and economic effects of a "Table fieldFish pond" (TFFP) land use scheme in Lijin County in the Yellow River Delta of China with reference to the optimization of ecological-productive structures resulting from a land use / land cover change (LUCC) approach. "Table fieldFish pond" is an effective reconstructed land use system and eco-agricultural pattern to change low-lying saline land and fragile eco-environment. As an important human initiative, the LUCC at regional scale promote sustainable land use, promote eco-environmental improvement, provide productive structural regulation, and support sustainable economic development practices.
\end{abstract}

Keywords: $\quad$ land use / land cover change (LUCC); effect; "Table field-Fish pond" (TFFP) land use pattern; Yellow River Delta; China

\section{INTRODUCTION}

Land use / land cover change (LUCC) is one of the more significant issues between physical and human processes, embodying the essence of human-

Please use the following format when citing this chapter:

Xu, X., Duan, X., Dawson, R., Liu, Y., He, Y., Peng, H. and Cui, C., 2009, in IFIP International Federation for Information Processing, Volume 293, Computer and Computing Technologies in Agriculture II, Volume 1, eds. D. Li, Z. Chunjiang, (Boston: Springer), pp. 431-441. 
land relations (Ingram J. \& Matson P. 1998; Physical Geographical Committee, 1999). LUCC has been designated as a core field of study by the International Geosphere-Biosphere Programme (IGBP) and the International Human Dimensions Programme on Global Environmental Change (IHDP), and has therefore received great attention from scholar worldwide (Turner et al., 1995; Li, 1996; IGBP, IHDP \& WCRP, 2001). In trying to better understand LUCC issues, researchers should give some attention to qualitative changes within the soil matrix as well as the ecological effects of such changes in addition to the attention already given to dynamic interactions and driving force analysis of quantitative changes (Leng and Li, 1999; Guo et al., 2001; Xu et al., 2001). There is also need for additional study at a variety of scales on relations between LUCC and other issues such as global environmental change, regional sustainable development, and local ecological improvements and the mechanisms necessary for their implementation. The purpose of this research is to use the LUCC approach to examine the environmental, economic and social effects of the "Table field-Fish pond" land use reconstruction patterns on the saline lands of the Yellow River Delta, China, as well as discuss regional structural optimization of ecological-production resulting from LUCC.

The study region is Lijin County in the Yellow River Delta where is one of the new developing regions in China with great potential in resources, but a rather frail ecological environment. It is also an important national agricultural production base. Within this region, there is a large stretch of land that has yet to be exploited due to a number of restrictive factors; such as shallow heavy mineralized ground water levels, salinized soils, frequent droughts, and limited fresh water supplies due to interruption in the Yellow River flow during low flow seasons. In overcoming these conditions, local farmers created the "Table field-Fish pond" (TFFP) land use system; locally known as "farming up-fishing down."

The TFFP system involves digging deep ponds to breed fish and using the burden from the ponds to build high table-fields for cultivating crops. The system has been practiced in the Yellow River delta region and in other lowlying saline belts. The table-fields drop the groundwater level relatively speaking, while the saline lands are transformed using fresh water to rinse and remove the salt. As practiced, the "farming up-fishing down" approach is a tri-dimensional cultivation system used to increase the efficiency of land use. At regional scale, the land use and land cover changes result in a series of changes in ecological environment and economy. 


\section{STUDY METHODS}

We use the methods combining natural and human sciences, which including:

(1) On the basis of analyzing the structure of the TFFP land use pattern, we calculate the areas of land use types before implementing TFFP (1991) and after popularizing TFFP (1998) in Lijin County to understand the land use and land cover changes at regional scale.

(2) To review the ecological effects of the TFFP land use pattern, soil samples from reconstructed table fields and nearby original saline lands, as checking points, were collected and tested. At each location, soil was collected from a profile of $0-30 \mathrm{~cm}$ in depth, taken samples at surface, $10 \mathrm{~cm}$ and $30 \mathrm{~cm}$ respectively; 3 pieces of soil were picked and then mixed into one single sample. Because the level of salinization and the organic content are the key indicators of land quality in the Yellow River Delta region, our soil analysis focuses on these two indicators. The level of salinization was measured by testing the conductance of the salt contents in soil solution; the organic content was measured using the method of potassium dichromate. We also analysed other ecological effects of TFFP at regional scale.

(3) In fact, TFFP land use pattern is an eco-agricultural scheme. The LUCC bring the changes of production structure. We compare the structure of product value in Lijin County in 1991 to those in 2005 to show productive structural regulation. And farther more, we design a perfect eco-agricultural model of "table filed-fish pond".

(4) By means of investigation and calculate the gross output value of agriculture (including farming, forestry, animal husbandry and fishery) in Lijin County and Chenzhuang Town, a demonstration district of TFFP, at the end of different years, so as to know the economic and social effects of TFFP contributing to local economic development. At a TFFP unit scale, input-output analysis is applied to evaluate the economic income based on the peasant household survey.

\section{RESULT ANALYSIS}

\subsection{Basic structure of TFFP land use pattern and regional LUCC}

The typical TFFP land use system has a structure of "442" framework, where the area of the pond, table field, and road and ditch zone occupies 
$40 \%, 40 \%$, and $20 \%$ of the overall area respectively. Because the threshold value restricting the rise of salt content in the local sandy soil in the area is about $1.5 \mathrm{~m}$, the table field must be no less than $2 \mathrm{~m}$. The normal structure of the pattern is shown as Figure 1.

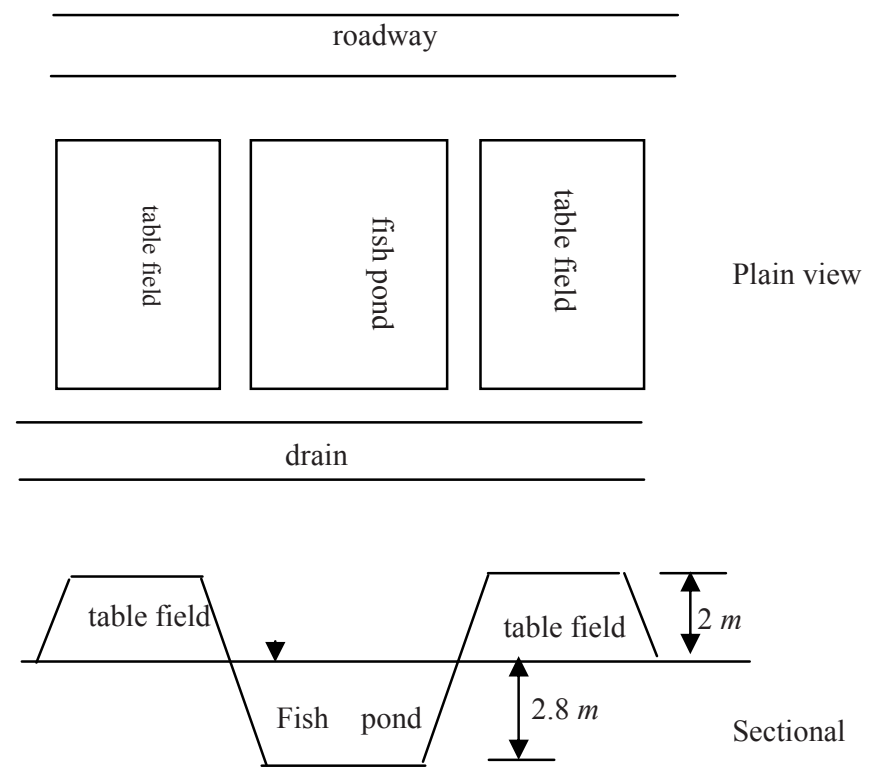

Fig 1: Basic structure of "Table field-fish pond" land use pattern

Table 1. Area changes of land use / cover in Lijin County

\begin{tabular}{lcc}
\hline \multicolumn{1}{c}{ Year } & 1991 & 1998 \\
\hline Farmland & 57291 & 53051 \\
Garden & 368 & 1406 \\
Woodland & 1833 & 1575 \\
Grassland & 2603 & 2137 \\
Settlement \& industrial land & 9330 & 10620 \\
Traffic land & 1826 & 2217 \\
Water area & 28694 & 32573 \\
In which: pond & 2981 & 3734 \\
Unused land & 26696 & 25112 \\
In which: wasteland & 3541 & 2751 \\
Saline & 22718 & 21791 \\
Total area & 128691 & 128691 \\
\hline
\end{tabular}

Source of data: the land management Bureau of Shandong Province, China

At regional scale, popularizing TFFP land use pattern has resulted in land use and land cover changes. Table 1 presents the findings from a comparison 
of land use/land cover in Lijin county in 1991 (without the TFFP system) to the same area in 1998 with the TFFP system in use. Several obvious changes can be seen relative to the development of TFFP system, especially the reduction in waste and saline lands, and the increase in ponds and freshwater agriculture.

\subsection{LUCC and ecological effects}

We checked many reconstructed fields' effects by soil samples. For one example, Table 2 presents the results for soil samples collected in a field managed by Mr. Jiabing Guo, a common farmer.

Table 2. Testing results of soil samples for "Table field - Fish pond" effects

\begin{tabular}{ccccc}
\hline Mark of samples & Depth & Organic matter $(\%)$ & Salt content (\%) & Remark \\
\hline $\mathbf{L}_{\mathbf{1}}-1$ & Surface soil & 0.983 & 0.058 & Table field, vegetable \\
$\mathrm{L}_{1}-2$ & $10 \mathrm{~cm}$ & 0.571 & 0.650 & \\
$\mathrm{~L}_{1}-3$ & $30 \mathrm{~cm}$ & 0.790 & 0.340 & \\
$\mathbf{L}_{2}-1$ & Surface soil & 0.570 & 0.890 & Table field, reed \\
$\mathrm{L}_{2}-2$ & $10 \mathrm{~cm}$ & 0.695 & 2.060 & \\
$\mathrm{~L}_{2}-3$ & $30 \mathrm{~cm}$ & 0.320 & 0.790 & \\
$\mathbf{L}_{3}-1$ & Surface soil & 1.020 & 2.030 & Saline (checking point to $\left.\mathrm{L}_{1}, \mathrm{~L}_{2}\right)$ \\
$\mathrm{L}_{3}-2$ & $10 \mathrm{~cm}$ & 0.530 & 2.410 & \\
$\mathrm{~L}_{3}-3$ & $30 \mathrm{~cm}$ & 1.200 & 0.270 & \\
$\mathbf{L}_{\mathbf{4}}-1$ & Surface soil & 0.517 & 0.046 & Table field, maize \& bean \\
$\mathrm{L}_{4}-2$ & $10 \mathrm{~cm}$ & 0.220 & 0.048 & \\
$\mathrm{~L}_{4}-3$ & $30 \mathrm{~cm}$ & 0.230 & 0.067 & \\
$\mathbf{L}_{5}-1$ & Surface soil & 0.580 & 2.600 & wasteland (checking point to $\mathrm{L}_{4}$ ) \\
$\mathrm{L}_{5}-2$ & $10 \mathrm{~cm}$ & 0.290 & 1.220 & \\
$\mathrm{~L}_{5}-3$ & $30 \mathrm{~cm}$ & 0.600 & 0.750 & \\
\hline
\end{tabular}

A comparison of points in the original saline lands with table fields indicates that the saline content has decreased as well as the amount of organic matter. The TFFP pattern has effectively changed the major restrictive factor - too much saline in the original land. During the initial stages, however, soil organic matter may decrease because the original topsoil is often covered by new soil when digging the ponds and building the table fields. Interviews with local farmers helped clarify the observed differences among the three samples $\mathrm{L}_{1}, \mathrm{~L}_{2}$, and $\mathrm{L}_{3}$. $\mathrm{L}_{1}$ and $\mathrm{L}_{2}$ came from different plots in the same table field. The crops from this field did not grow well because the soil was poorly ventilated as the field was built by slurry pumping and deposition four years earlier. Site $L_{1}$ is in a vegetable plot where salinity had decreased and organic matter accumulated because of intensive cultivation. $\mathrm{L}_{2}$ was a barren uncultivated plot, whose salinity was 
reduced in the surface soil because of eluviation from rainwater. The table field with sample $\mathrm{L}_{4}$ was built one year before by an excavator. The soil is ventilated and maize, soybeans and asparagus are intercropped and growing well.

Besides improving saline soils, the TFFP land use pattern has other ecological effects. Because the ponds coexist with table fields, they serve as small reservoirs. Because they store fresh water, they are able to supply the necessary cultivation water in dry seasons or when the Yellow River flow is interrupted. For example, in 1997 and 1998, there was a severe drought and the ordinary farmlands all decreased in output. Table lands, on the other hand, all had good harvests in addition to the output from fishing in the ponds. The TFFP system is able to serve as a sustainable land use pattern through consistent yields because it provides irrigation during drought and draining when waterlogged. In addition, the local microclimate has higher relative humidity levels because of the added moisture from the ponds.

\subsection{LUCC and regulation in the structure of production}

The application of LUCC analysis to the TFFP pattern has led to changes in the structure of production. The comparison of product value shares for the farming, forestry, animal husbandry and fishery industries in Lijin County in 1991 to those in 2005 are presented in Figure 2.

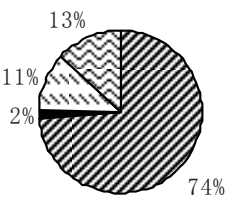

1991

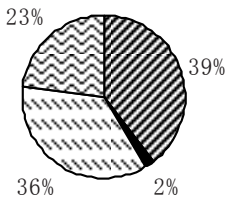

2005

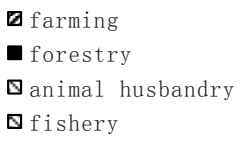

曰

Fig. 2: Agricultural productive structure from 1991 to 2005 in Lijin County (Source of data: The Statistics Bureau of Lijin County.(1991) Statistical data in Lijin county; The Statistics Bureau of Lijin County.(2006) Lijin Statistical Yearbook.)

Naturally, the changes identified above are related to agricultural policy, but the development of fishery sector is a direct benefit of the new land use pattern. In 1991, fresh water agriculture occupied only $5.92 \%$ of the fishery product share, but increased to $33.71 \%$ in 2005 as a result of the TFFP land 
use system. The TFFP system has changed both the regional land use structure and pattern of production as the areas devoted to agricultural have increased from 533ha in 1991 to $4667 h a$ in 2005. As the useable land increase, more areas can be used for animal husbandry to gain higher benefits instead of simplex used for farming. Thus, agricultural productive structure has changed in the whole county.

\subsection{LUCC and economic and social effects}

\section{(1) Economic effects}

Figure 3 shows the changes of gross output value of agriculture in Lijin County:

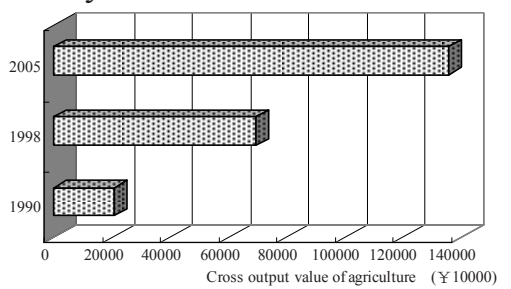

(1)

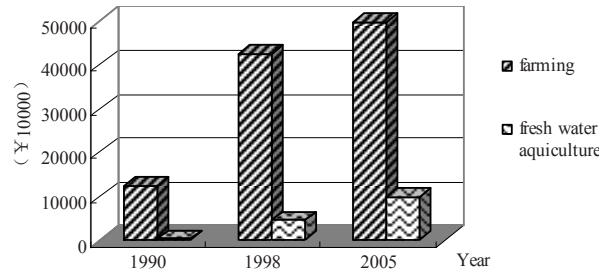

(2)

Fig. 3: Rise of the gross output value of agriculture (1) and output value of farming and fresh water aquiculture (2) in Lijin county (at the 1990's constant price)

The gross output value of agriculture has increased from $¥ 206.92$ million $R M B$ in 1990 to $¥ 2224.48$ million $R M B$ in 2005 ( $¥ 1354.56$ million $R M B$ in constant $R M B$ terms). Moreover, related to TFFP, the output value of farming in 2005 is 4.05 times greater than that in 1990, and the output value of fresh water aquiculture in 2005 had reached 38.96 times as much as that in 1990 (at the 1990's constant price). In Chenzhuang Town, a demonstration district utilizing the "farming up-fishing down" pattern, 1990 gross output from agriculture value was $¥ 7.22$ million $R M B$ without a fresh water agriculture component. In 2005 agricultural output reached $¥ 242.36$ million $R M B$, including $¥ 48.36$ million $R M B$ (in 1990’s constant $R M B$ terms) from fresh water fisheries. The change on the gross output value and structure of farming, forestry, animal husbandry and fishery in Chenzhuang Town are shown in Figure 4. 


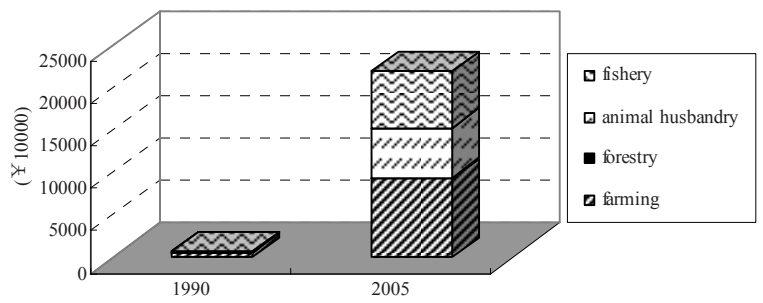

Fig. 4: Changes in the gross output value and structure of agriculture (including farming, forestry, animal husbandry and fishery) in Chenzhuang Town in Lijin county(at the 1990's constant price)

In 1998, the gross domestic product value from all sources in Chengzhuang Town was $¥ 1.25$ billion $R M B$, with the area devoted to TFFP amounting to $10,000 \mathrm{mu}$ (667ha) and gross aquatic output reaching 1,040,000 $\mathrm{kg}$. Primary products from the TFFP system included asparagus, earthnut, grape, melon and vegetables, whose total production was $¥ 19$ million $R M B$ with a net profit of $¥ 8.9$ million $R M B$. On a per farmer basis, net income was 4.7 times greater than in 1990 .

According to the peasant household survey, averagely a peasant household with 3 or 4 members can gain about $¥ 107850 R M B$ income from a "442" TFFP unit (plant cotton in the table field). The ratio of output to input is 1.92 for the total unit. Respectively, the ratio of output to input of table field (2.80) is higher than that of fish pond (1.78). The engineering cost of a " 442 ” TFFP unit is about $¥ 81000 R M B$, which means the investment can be recouped in one year. At present, the "cotton field-fish pond" agricultural pattern becomes one of the most popular production modes. The detailed input-output data is shown in Table 3.

Table 3. The currency input-output of a " 442 " TFFP unit in 2006

\begin{tabular}{clclc}
\hline \multicolumn{1}{c}{ Items } & \multicolumn{2}{c}{ Fish pond } \\
\cline { 2 - 5 } & \multicolumn{1}{c}{ Cotue (RMB) } & \multicolumn{1}{c}{ Items } & Value (RMB) \\
\hline \multirow{6}{*}{ Cotton seed } & 750 & Fry & 15000 \\
& Soil fertilizer & 6000 & Feed & 19500 \\
& Irrigative water & 450 & Water fertilizer & 10500 \\
& Agricultural machinery & 1200 & Pond water & 15000 \\
& Plastic film & 750 & Electricity charge & 1500 \\
& Electricity charge & 300 & Medication & 5100 \\
& Pesticide & 600 & Labour force & 10500 \\
& Transport cost & 3000 & Transport cost & 18000 \\
& Others & 3000 & Others & 6000 \\
Oncome & Total & 16050 & Total & 101100 \\
\cline { 2 - 5 } & Cotton & 45000 & Fish & 180000 \\
\cline { 2 - 5 } & & & & 78900 \\
\hline
\end{tabular}




\section{(2) Social effects}

Meanwhile, the exploitation of the "farming up-fishing down" pattern has also brought out good social effects. For instance, in Chenzhuang Town, the local government established the developing policy and mechanism: "make uniform planning, exploit wasteland piece by piece, reconstruct table land to transform soil salinity, combine fishery with farming" and "service from the government, management by village committee, operation by contractor". That is, the government unifies the criteria and constructs the basic establishments such as production roads, culverts and water gates, pumping stations, and also spread new techniques.

Because the TFFP agricultural pattern effectively improved the low-lying soil quality and created much benefit for local residents, large area of saline land was exploited. The demand of labor force provided many employment opportunities for rural idle labors. At the same time, some youth labors who flowed to developed regions was attracted back to their hometown. Because the government has really served for farmers, the prestige of the government has advanced, and also has brought a closer relation between the governors and the masses.

\section{DISCUSSION}

While the TFFP system of land use has seen significant increases in production and economic value where applied, there are difficulties. The TFFP approach must find solutions to the following issues: (1) the marginal slope of the table field is apt to collapse, (2) table fields built by means of pumping and depositing with a slurry pump are slow to mature because of bad ventilation in the soil, (3) changing saline land into a "Table field-Fish pond" system has a high initial cost, making it difficult to implement without the support of government., and (4) the impact increasing output might put on driving prices lower.

In view of the above problems, several relevant countermeasures might be adopted: (1) cover vegetation over the marginal slope of table field to control collapse and soil erosion, (2) build table fields using an excavator; if pumping and depositing method are used, implement deep ploughing and intensive cultivation, (3) explore the capital circulation mechanism for exploiting waste lands with a view toward collecting, regulating and reclaiming the capital, and (4) according to the different periods of desalinization, cultivate different crops or other plants in the table fields and implement intercropping and inter-planting. 


\section{CONCLUSION}

The analysis of the effects of land use and land cover changes resulting from the development of the "Table field - Fish pond" land use pattern has led to the following conclusions:

(1) "Table field-Fish pond" is an effective land use system and ecoagricultural pattern to change low-lying saline land use structure while sustaining the fragile ecological environment.

(2) Large-area development of the "Table field-Fish pond" land use pattern has led to a regional LUCC approach and a series of ecological, economic, and social effects resulting in a more efficient regulation and optimization of the structure of production.

(3) Through human initiatives, LUCC studies help advance sustainable land use, improve the ecological environment, provide regulation and optimization in the regional structure of ecological-production, and support sustainable economic development.

\section{ACKNOWLEDGEMENT}

This research is a part of projects 40671001 \& 49771005 funded by National Science Foundation of China (NSFC), and also supported by the open program fund from the Laboratory for Earth Surface Process, Ministry of Education. The authors kindly acknowledge the NSFC committee and the laboratory for their supports. They also thank Ms. Huiping LIN, Ms. Yu He and Mr. Qiang XIE for taking part in collecting soil samples in the field works, and many local governors and farmers for introducing status of the "Table field-fish pond" land use pattern.

\section{REFERENCES}

Acta Geographica Sinice. 51(6): 551-557. (in Chinese)

Guo X., Fu B., Chen L., et al., 2001: Effects of land use on soil quality in a hilly area-a case study in Zunhua County of Hebei Province in China. Acta Geographica Sinica. 56(4): 447455. (in Chinese)

IGBP, IHDP \& WCRP, 2001: Abstract of Scientific Paper and Posters Presented at the Global Change Open Science Conference "Challenges of a Changing Earth", 10-13 July, Amsterdam, The Netherlands, pp.443.

Ingram J., Matson P., 1998: SAC V Synthesis Group Report. IGBP Newsletter No. 36. IGBP Secretariat, Stockholm, Sweden, pp.4. 
Leng S., Li X., 1999: New progress of international study on land quality indicators. Acta Geographica Sinica. 54(2): 177-85. (in Chinese)

Li X., 1996: A review of the international researches on land use / land cover change.

Physical Geographical Committee, 1999: Respect and forecast for integrated

physical geography of China in 1990s. In: Wu H., Liu C., Wu L.(eds), Chinese Geography at Transition of Centuries. People's Education Press, Beijing, pp. 12-15. (in Chinese)

Stochkholm .

Turner II B. L., Skole D., Sanderson S., et al., 1995: Land-use and land-cover change science/research plan, IGBP Report No.35 and IHDP Report No.7. IGBP,

Xu X., Guo H., Chen X., Lin H., 2002: A Multi-Scale Study on Land Use and Land Cover Quality Change: The Case of the Yellow River Delta in China. GeoJoural, 56 (3): 177-183. 